\title{
Assessing Social and Spatial Equity of Neighborhood Retail and Service Access in Seoul, South Korea
}

\author{
Donghyun Kim and Jina Park * \\ Department of Urban Planning and Engineering, Hanyang University, Seoul 04763, Korea; \\ hyunurban@hanyang.ac.kr \\ * Correspondence: paran42@hanyang.ac.kr; Tel.: +82-2-2220-0332
}

Received: 27 September 2020; Accepted: 13 October 2020; Published: 15 October 2020

check for updates

\begin{abstract}
Creating a sustainable urban space should allow everyone to benefit from urbanization regardless of their ability. Spatial equity is one of the significant factors of sustainability. Several studies have explored pedestrian accessibility and spatial equity, but few researchers have addressed daily retail activities. This study aimed to examine the equity of pedestrian accessibility to neighborhood retail and service (NRS) establishments in Seoul, Korea. Accessibility of NRSs was measured by pedestrian direction API and spatially clustered by local indicators of spatial association (LISA). Equity was examined using the Mann-Whitney $U$ test to test the difference between socioeconomic and built environment variables between high and low accessibility areas. We found that vulnerable groups favored access to the NRSs over more affluent groups. This study's results suggest that urban planners and designers should contemplate ways to enhance the walkability of the residents and continually monitor accessibility to prevent urban problems, such as food deserts and retail deserts. Additionally, the results provide empirical evidence for achieving equity in urban development and urban retail systems to further enhance sustainability.
\end{abstract}

Keywords: accessibility; equity; neighborhood retail; pedestrian directions API; walkable city; socially disadvantaged group; socioeconomic status

\section{Introduction}

Creating a sustainable urban space aims to create a variety of environments on a human scale so that everyone can benefit from urbanization to achieve a more livable city regardless of their abilities [1]. Walkability based on the human scale is one of the main factors for making a livable city [2]. Walkability has received much attention because of its essential advantages in the economy and health of the city [3]. A critical issue related to walkability is accessibility for socially vulnerable people, such as low-income and older people with mobility difficulties. Low-income seniors living alone with a monthly income of less than US $\$ 1,000$ are the most vulnerable in Seoul, walking or biking on $67.8 \%$ of their trips. Because walking is the primary mode of travel for people who cannot use various transportation due to physical or economic difficulties, improving walkability is part of social welfare. Additionally, improving accessibility for pedestrians, considering traffic weakness, improves the city for all.

The most common place types for retail activity are neighborhood retail and services (NRSs), including grocery stores, convenience stores, and laundry facilities. NRSs provide daily necessities and services to meet the needs of residents and consumers and are essential for neighborhood sustainability and settlement with public goods [4]. NRSs not only sell products and provide services but also play various roles in the neighborhood. NRSs have a positive effect on neighborhood perception through social activities [5]. In particular, supermarkets in Korea sell food and daily necessities, and they are the center of neighborhoods where social activities such as social exchange, information exchange, 
and leisure activities occur most frequently [6]. Unlike public services, NRSs are a part of the private sector, but the structure and location of the city as a result of planning and regulation determine the access that affects its use [7]. In particular, NRSs need to be focused on walking accessibility, highly available to all citizens, and closely related to everyday life.

Fair distribution of access to goods and services across the city is a fundamental right of urban citizens $[8,9]$. Differences in neighborhoods with access to daily activities can lead to significant inequality for residents. Therefore, it is necessary to identify and cope with differences in accessibility according to the socioeconomic and spatial characteristics of neighborhoods. Socially vulnerable residents can experience relatively significant inequalities related to social exclusion. Goods and services that are essential for everyday life should be distributed evenly in space, but the availability according to the socioeconomic characteristics of the population must be taken into account. In other words, access to NRSs should be planned in terms of equality of opportunity beyond social equality based on the characteristics of the residents. It will qualitatively improve the retail landscape and is the basis of sustainable urban development. In this regard, many studies have been conducted using the term "desert" extensively in areas where essential services, such as food access, banking, and books, are lacking [10-12]. Pedestrian accessibility is the least expensive and most essential accessibility. Evaluating the equity of pedestrian accessibility means assessing the most basic accessibility. Equity can be classified mainly into horizontal equity and vertical equity. Horizontal equity is the concept that everyone should be equitably distributed under the same circumstances. Vertical equity, however, is evaluated differently according to the socioeconomic situation (SES) of groups. It is concerned with different conditions of various groups, including the elderly, the disabled, and low-income people [13]. While horizontal equity of accessibility is significant because it is a necessary facility for everyone, in terms of equality of opportunity, NRSs also need to be concerned about vertical equity, taking into account the relative accessibility for socially vulnerable groups.

Access to NRSs in Seoul has been affected by changes in the retail environment. Since E-mart's first store opened in 1993, large discount stores selling various items at low prices have been built here and there in the city. Large discount stores have created a buying spree on weekends rather than buying little by little in neighborhood corner shops. In the 2000s, the rapid spread of the internet increased the size of online retailing seven times from 2005 to 2015, allowing consumers to quickly order items with a click and receive them through delivery services. Such large discount stores and shopping websites have replaced the demands of neighborhood commerce by changing consumer consumption. In 2010, as smartphones became popular, the platform business emerged, and it is replacing the service industry in the neighborhood with professionalism and outreach services [14]. Recently, the unique scenery of the old neighborhood has become popular, and there is a commercial gentrification phenomenon where art galleries, boutiques, and cafes replace NRSs in the neighborhoods. The main feature of recent commercial gentrification in Seoul is that it takes place in NRS-oriented shopping streets in residential areas, and it causes cafes, Western restaurants, and chain retailers to replace NRSs on the shopping street. New shops on the street where commercial gentrification has occurred focus more on the demand of outside visitors than on residents, resulting in less access to goods and services for residents $[15,16]$. Although these changes to the commercial environment are inevitable, the spatial differences in the everyday goods and services that are involved need to be discussed [10]. In this regard, there is a growing voice that policy should be established for NRSs.

Several researchers have studied NRS equity of accessibility in different cities throughout the world [17-19]. Schuetz, Kolko, and Meltzer (2012) examined the association between various categories of NRS density and neighborhood income in American cities. Arranz-López, Soria-Lara, and Pueyo-Campos (2019) used a GIS network analysis to assess the social and spatial equity effects of NRS accessibility. Garcia, Garcia-Sierra, and Domene (2020) employed a spatial clustering method to explore the relationship between local food environments and different social groups. However, we found no study combining the accessibility to various categories of NRSs by different social groups with spatial clustering methods. This study aims at filling this gap using Seoul as a case study. 
In this study, we combine the use of pedestrian direction API-based measurements to study the accessibility of categories of NRSs by different urban planning conditions with the use of spatial clustering methods. We investigate the relationship between the spatial equity of neighborhood stores and the socioeconomic variables of a specific region according to Talen's framework [20], which examined this relationship with socioeconomic and built environment characteristics by measuring accessibility. Our procedure consists of three steps. The first step is to measure accessibility using the pedestrian route web API. The accessibility value of each census tract unit is mapped and spatially clustered using the local indicators of spatial association (LISA) statistical technique. Finally, the 2-sample test (Mann-Whitney $U$ test) is performed to investigate whether there is a difference in socioeconomic and built environment characteristics between high access tracts and low tracts. We focus on social groups that may derive more benefits from the frequent patronage to NRSs, such as the seniors and those residing in the lower-income neighborhoods of the city. Our results may provide useful insights for neighborhood planning in an equitable manner.

\section{Materials and Methods}

\subsection{Materials}

\subsubsection{Study Area}

Seoul is the largest and most populous city in Korea. Seoul is surrounded by mountains and is divided into two areas called Gangbuk and Gangnam because of the Han River located in the center of the city(Figure 1). Administratively, Seoul comprises 25 boroughs and 423 administrative buildings. Seoul was built around the north of the Han River as the capital in the late 14th century. After the Japanese colonial period and the Korean War, the population rapidly increased, expanding to the northeastern and south side of the Han River, and the city rapidly underwent urbanization. In the process of urbanization, various urban structures were formed according to the period. The old city center has a network of pedestrian-oriented road networks, and the roads of the car-centered roads are overlaid. The newly built northeastern and southern parts of the Han River were constructed with large superblock centers for cars and public transportation. The old neighborhoods of Seoul before the 1960s were low-rise, low-density areas, but as the population grew rapidly, buildings were built upon smaller parcels and blocks, transforming them into low-level, high-density areas. Meanwhile, from the 1970s, neighborhoods were constructed as large apartment complexes in both newly constructed neighborhoods and old redeveloped neighborhoods. Seoul, which was constructed in such a short time, responded to demand more quickly than planned. This caused an imbalance in the urban structure of Seoul.

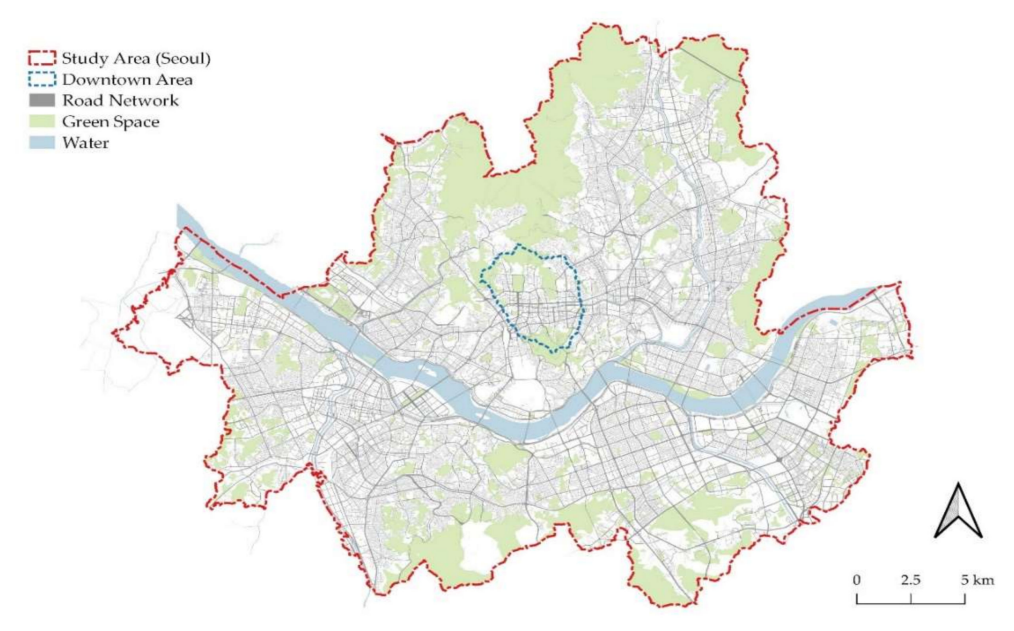

Figure 1. Study area (Seoul). 


\subsubsection{Walking Time Measurement Using NRS Location Data and API}

Our primary source of data on NRSs was the retail location dataset collected from the Our Town Industry Service of Statistics Korea. The retail location data provided the specific location of 36 businesses; however, store information, such as the number of employees or size of the floor space, was not provided to protect the individual store's privacy. The neighborhood living facilities as prescribed by the Korean Building Law were too broad to meet the purposes of this study. Therefore, we selected business types that met the concepts of necessity and frequency used by Meltzer and Capperis [21]. NRSs supply consumers' daily needs (necessity) and provide frequently consumed goods or services (frequency). For this reason, they should be associated with short travel times, that is, high accessibility. We chose seven types of businesses that match the concept of NRSs (Appendix A).

All seven industries were closely related to daily life, but there were differences in characteristics between industries. When correcting for this, more accurate accessibility can be derived. In general, when measuring accessibility, we considered the size of the destination's space. However, the business location data used in this study provided a specific location of a store, and as mentioned, store information such as the number of employees or space size is not provided to protect the privacy of individual stores. Therefore, the average number of employees and business hours by business type in Seoul provided by the Service Industry Survey was weighted. The frequency of visits by Seoul citizens to purchase daily services and daily necessities, which was surveyed by Park (2016) [22], was also used as a weight (Table 1).

Table 1. Characteristics differences between categories and applied access weights.

\begin{tabular}{|c|c|c|c|c|c|c|c|}
\hline \multirow{2}{*}{ Variable } & \multicolumn{2}{|c|}{ Scale } & \multicolumn{2}{|c|}{ Opening Hours } & \multicolumn{2}{|c|}{ Freq. of Visit } & \multirow{2}{*}{$\begin{array}{c}\text { Final } \\
\text { Weight }\end{array}$} \\
\hline & $\begin{array}{l}\text { Num. of } \\
\text { Employee }\end{array}$ & Weight & $\begin{array}{l}\text { Hours/ } \\
\text { Week }\end{array}$ & Weight & $\begin{array}{l}\text { Times/ } \\
\text { Week }\end{array}$ & Weight & \\
\hline Barber shop & 1.18 & 1 & 73 & 1.05 & 2.12 & 1 & 1.01 \\
\hline Beauty salon & 2.08 & 1.76 & 70 & 1.01 & 2.12 & 1 & 1.45 \\
\hline Laundry service & 1.56 & 1.32 & 80 & 1.15 & 2.12 & 1 & 1.22 \\
\hline Convenience store & 4.40 & 3.72 & 133 & 1.92 & 4.65 & 2.19 & 3.05 \\
\hline Grocery store & 2.02 & 1.71 & 81 & 1.17 & 4.65 & 2.19 & 1.70 \\
\hline Hardware store & 1.56 & 1.32 & 69 & 1 & 4.65 & 2.19 & 1.43 \\
\hline Supermarket & 10.86 & 9.18 & 96 & 1.39 & 4.65 & 2.19 & 6.22 \\
\hline
\end{tabular}

A brief description of the API used to collect data in this study is as follows: First, when a request is made with the coordinate values of two points as parameters in the pedestrian directions API provided by Naver (Gyeonggi, Korea), the information on the walking distance and walking time between the two points is provided. In addition, the API provides recommended routes that consider the effects of the facilities that affect walking, such as sidewalks, crosswalks, underpasses, ramps, and stairs. Therefore, the API can more accurately calculate the walking path, distance, and time of journey compared with the existing GIS network analysis. Using Python, a GET request was made, and the response in JSON format was parsed for analysis.

\subsubsection{Socioeconomic Characteristics}

The socioeconomic variables used to access equity in the access to NRSs refer to census tract-level for the year 2017 and were obtained from the Korea Statistics and Korea Credit Bureau. Income is one of the leading social and economic indicators that can be used to explain social inequality. In densely populated areas, the presence of more NRS is even more critical as a crowded NRS can affect the quality of the user experience. Moreover, the characteristics of the dependent population, such as the elderly and children, and household characteristics, such as single-person households, are important consumer characteristics crucial for social equity and the commercial environment. 


\subsubsection{Built Environment Characteristics}

The built environment is created through urban planning and development, and it affects the location of houses and stores and the paths between them. Looking at the relationship between the accessibility of the NRS and the built environment can provide a new approach to urban planning. The built environment can be largely divided into land-use patterns and transportation systems. The type of housing is an essential element that helps form the pattern of land use. However, the same type may have different characteristics depending on the period of construction, which can be confirmed by the proportion of dilapidated dwellings. The morphological characteristics of urban transportation systems represented by road networks can be of various types, such as a grid type, an irregular shape, and a mixed type. One of the indicators determining the form of a road network is straightness, which is expressed as the ratio of the straight distance and the shortest path distance between two points [23]. Therefore, the value is between 0 and 1 . For example, if the straightness value is 0.7 , the straight distance is $70 \%$ of the shortest path distance; therefore, the pedestrian walks $30 \%$ more than the straight distance. This is because the road is more densely structured, thus making the walking path more efficient. Additionally, because the API considers the use of pedestrian facilities, we can infer the travel cost incurred to use the crossing facilities. In addition, the slope is a variable that affects the walking speed, and it is difficult to use a road with a severe slope, particularly for the vulnerable and elderly. We used digital eleveation model(DEM) data and GIS to calculate the average slope for each census tract.

\subsection{Methods}

\subsubsection{Measuring Accessibility to NRS}

In this study, we chose Talen's approach based on a gravity model that measures the level of access to characterize and compare the accessibility of NRSs, taking into account both the characteristics of NRSs and the distance to a neighboring store within a specific distance [20]. This methodology reflects the actual path through network-based accessibility measurement and can avoid the modifiable areal unit problem (MAUP) by measuring the access level accessible within a specific range in a small area. In this study, based on the walking time measured through API, stores accessible within a 10-min walk were targeted. The formula is as follows in Equation (1):

$$
A_{i}=\sum_{t[i, j] \leq 10} e^{-\beta \cdot t[i, j]}
$$

where $t[i, j]$ is the recommended walking time between origin $i$ (census blocks) and destination $j$ (stores), and $\beta$ is a variable to control the distance decay effect. Here, $\beta$ can be truncated depending on the type of vehicle and destination. The value was approximately 0.001 , which is used when measuring walking time.

\subsubsection{Assessing Social Equity}

The analysis method of this study was divided into two steps. First, we followed Anselin's approach using a single- and two-variable local spatial association indicator (LISA) to determine the existence of statistically significant spatial clusters [24]. LISA can identify patterns of association with the surroundings of individual locations, including hot spots and spatial outliers. The Local Moran I statistic (Ii) is defined as follows in Equation (2):

$$
I_{i}=\left(\frac{z_{i}}{\sum_{i} z_{i}^{2}}\right) \sum_{j} W_{i j} Z_{j}
$$

where $z_{i}$ and $z_{j}$ are expressed in deviations from the mean and $W_{i j}$ is the spatial weight. We used the open source software GeoDa [25] to conduct this test. 
Second, the Mann-Whitney U test was applied to identify the spatial distribution relationship between socioeconomic and built-environment characteristics and NRS access. The Mann-Whitney U test compares the socioeconomic characteristics and built-environment characteristics of the group with high accessibility and the group with low accessibility divided based on the above clustering results to test which group accessibility favors. The Z-scores have different meanings; negative values indicate that group 1 values tend to be smaller than group 2 values, whereas positive values indicate that group 1 values tend to be greater than group 2 values. The formula Mann-Whitney $U$ is as follows in Equation (3):

$$
U=n_{1} n_{2}+\frac{n_{2}\left(n_{2}+1\right)}{2}-\sum_{i=n_{2}+1}^{n_{2}} R_{i}
$$

where $n_{1}$ and $n_{2}$ refer to the sample size of each group, and $R_{i}$ is the rank of the sample. In this test, the null hypothesis ( $p$-value $>0.05$ ) is that there is no statistical difference between two groups (that could be identical), whereas the alternative hypothesis ( $p$-value $<0.05)$ establishes that there are statistical differences between the groups. In the context of this research, a rejection of the null hypothesis means that socioeconomic and built environment variables are relevant for the distribution of high and low accessibility to NRS. Otherwise, we conclude that such relation cannot be proven to exist. The combined results of these two methodologies will determine whether or not accessibility favors groups with particular socioeconomic characteristics over others [20].

\section{Results}

\subsection{Spatial Distribution and Clustering of Accessibility and Income}

A map of the quintiles for accessibility and income is shown in Figure 2. Accessibility has a quintile 5 (high accessibility) value in all communities, but it is clustered within the community. In terms of income, quintiles 5 (high income) exist in some areas of the city center, the southeastern, and the northeast regions (Jongno, Gangnam, Seocho, Songpa, Yeongdeungpo, Yangcheon, and Nowon), and quintiles 1 (low income) are in the southwestern and northeastern regions (Geumcheon, Guro, Jungnang, Dongdaemun, Sungbuk, and Gangbuk). The results of the univariate and bivariate LISA analyses are shown in Figure 3. Univariate LISA results show more clearly what was seen in the previous quintile map. High-high neighborhoods are clustered and seen within communities, which are mainly seen in the southern area of the Han River. Low-low neighborhoods mainly appear in the outer green areas or around the Han River. The bivariate LISA result is a spatial cluster that considers both accessibility and income, and the areas where accessibility and income are significantly correlated are derived. The high-high and low-high regions mainly appeared in downtown and business districts (Jongno, Joong, Gangnam, Seocho, and Yeongdeungpo), which can be seen as core regions of Seoul. There are 37 high-high areas, while 156 are more low-high areas. In other words, the regions with high incomes had more regions with low accessibility. Low-low and high-low regions were mainly found in the southwest and northeast (Gangbuk, Seongbuk, Jungnang, Geumcheon, and Guro). There were 156 low-low regions and slightly more than 142 high-low regions.

\subsection{Differences in the Distribution of Social Groups and Built Environment According to NRS Access}

Tables 2 and 3 show the median values of socioeconomic indicators and built environment characteristics for regions with high accessibility and low accessibility for the NRSs. To find out whether there are statistically significant differences in the distribution of specific social groups concerning NRS access, we used the Mann-Whitney U test for each socioeconomic characteristic. The Mann-Whitney $U$ test is a nonparametric test, and the null hypothesis is that there is no significant difference between the two regions for NRS accessibility. 


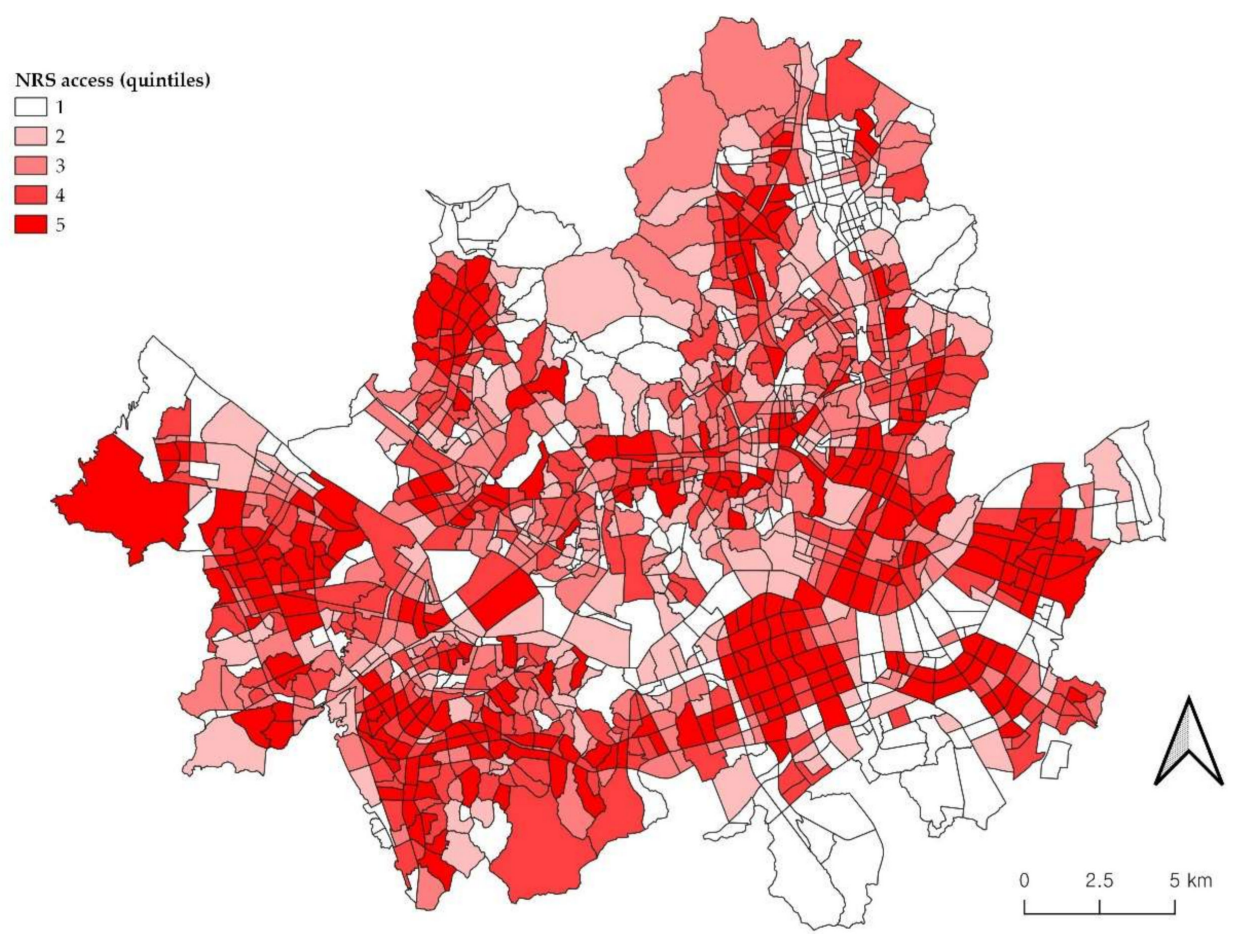

(a)

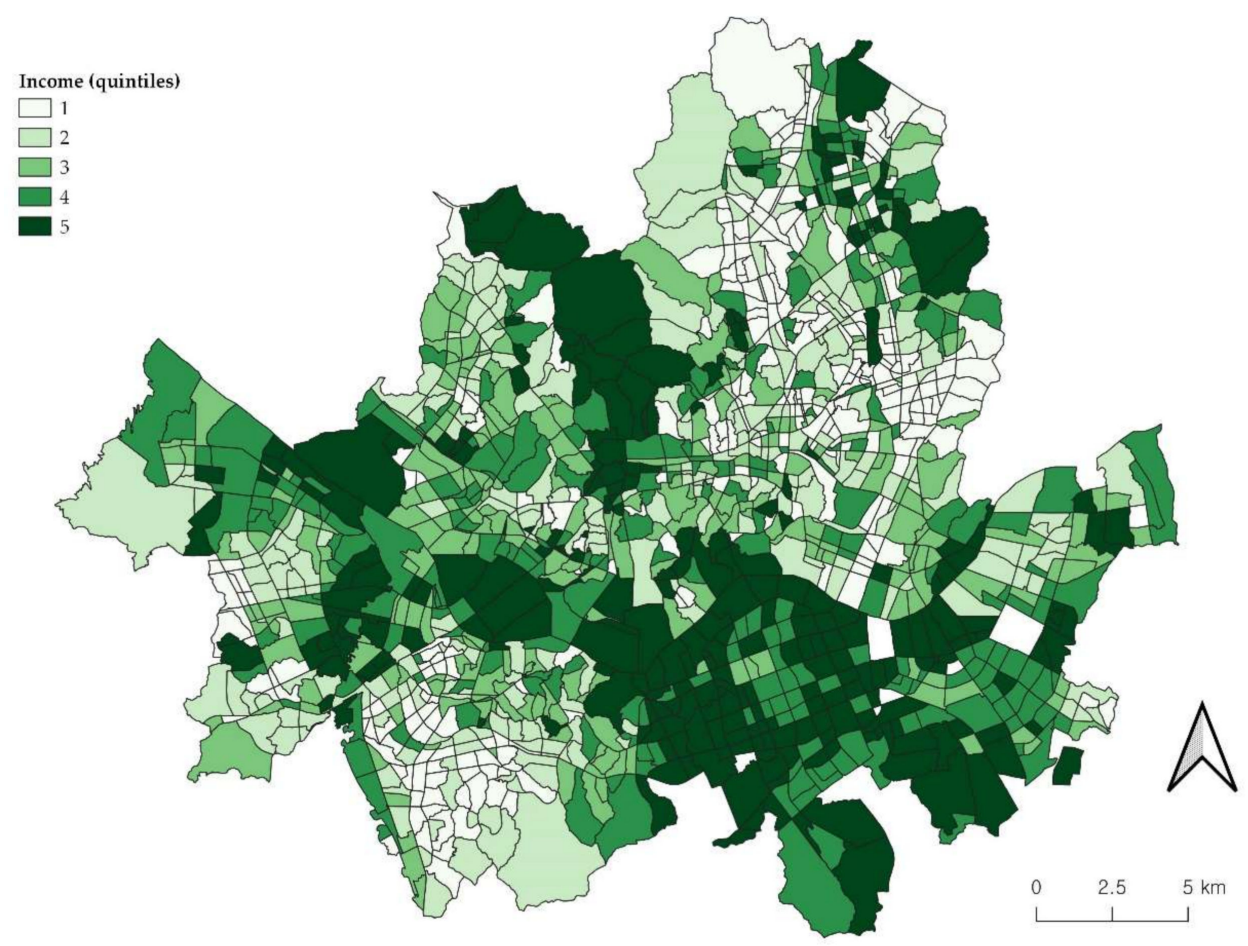

(b)

Figure 2. Quintiles map at census tract scale: (a) neighborhood retail and service (NRS) access; (b) income. 


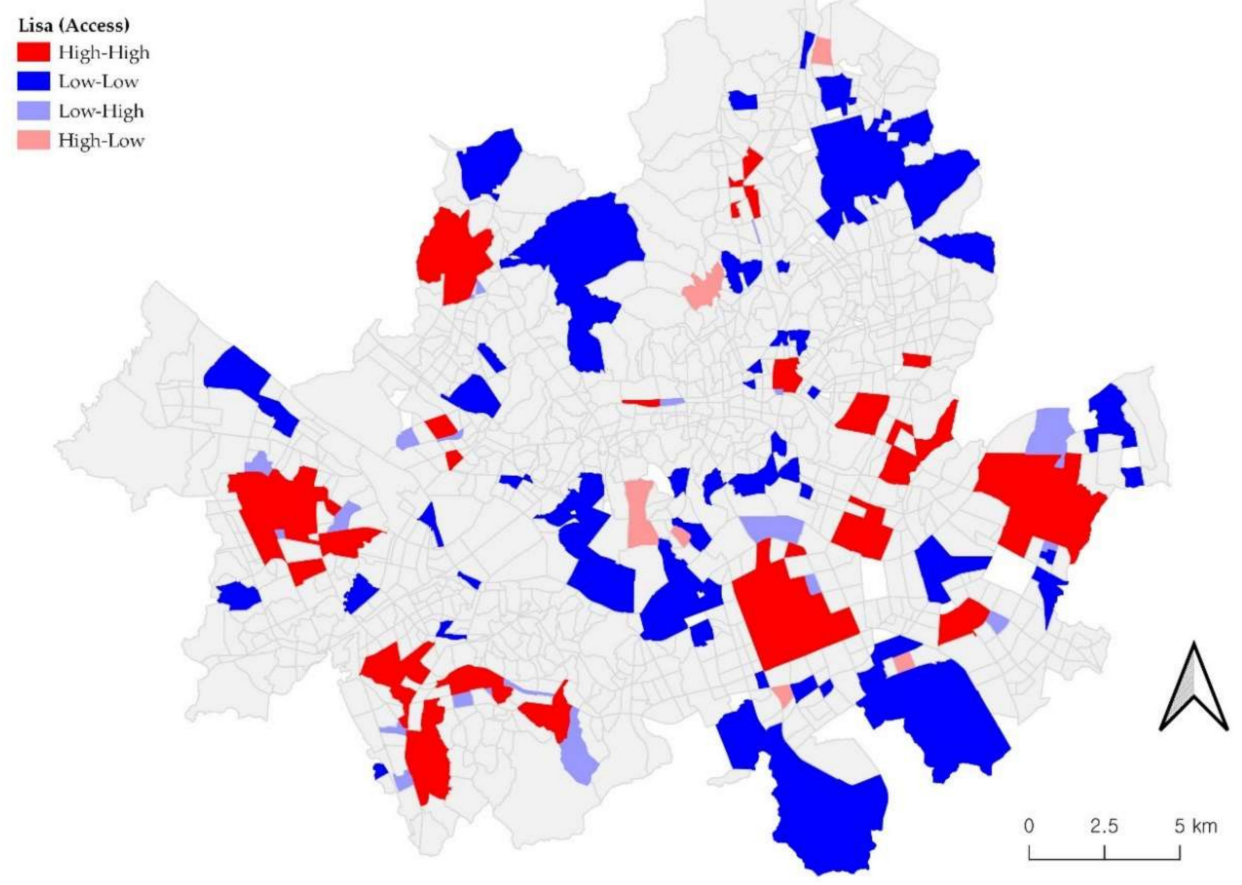

(a)

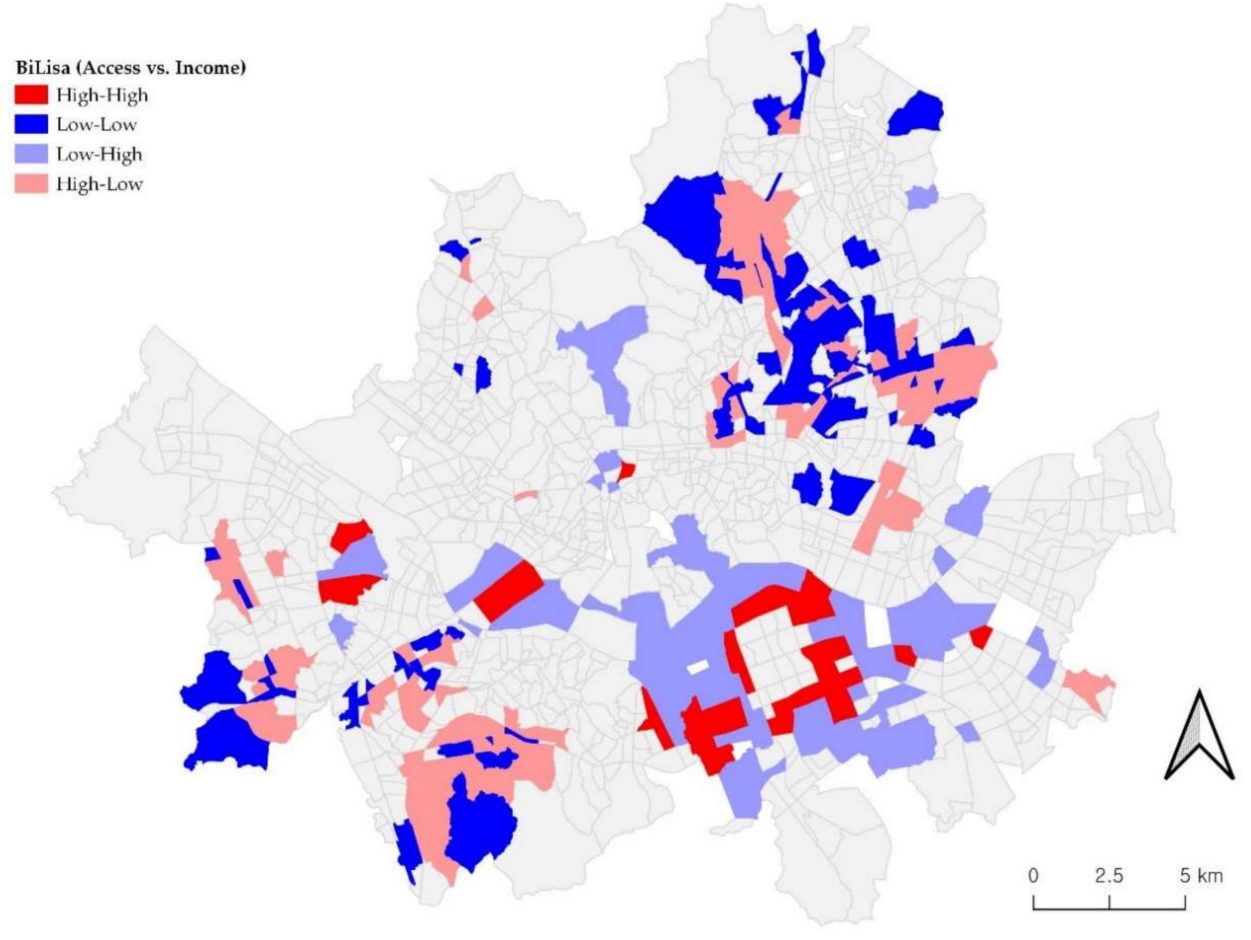

(b)

Figure 3. Local Indicators of Spatial Association (LISA) analyses result: (a) univariate; (b) bivariate. 
Table 2. The estimation of social groups in high and low access census tracts.

\begin{tabular}{ccccc}
\hline Variable & High Access & Low Access & \multicolumn{2}{c}{ Mann-Whitney U Test } \\
\cline { 4 - 5 } & & & $\mathbf{Z}$ & $\boldsymbol{p}$-Value \\
\hline Income & 2836 & 3397 & -10.299 & $0.000^{* * *}$ \\
Population density & 35,352 & 36,113 & 0.428 & 0.699 \\
Aged dependency ratio & 21.48 & 19.17 & 3.891 & $0.000^{* * *}$ \\
Child dependency ratio & 12.54 & 13.11 & -8.628 & $0.000^{* * *}$ \\
\%One-person household & 37.24 & 24.40 & 9.532 & $0.000^{* * *}$ \\
\hline
\end{tabular}

Table 3. Built environment in high and low access census tracts.

\begin{tabular}{ccccc}
\hline Variable & High Access & Low Access & \multicolumn{2}{c}{ Mann-Whitney U Test } \\
\cline { 4 - 5 } & & & $\mathbf{Z}$ & $\boldsymbol{p}$-Value \\
\hline \%Detached dwelling & 28.48 & 3.59 & 11.112 & $0.000^{* * *}$ \\
\%Apartment & 21.23 & 74.26 & -8.483 & $0.000^{* * *}$ \\
\%Multi-family dwelling & 37.10 & 13.23 & 5.775 & $0.000^{* * *}$ \\
\%Dilapidated dwelling & 7.08 & 1.43 & 5.529 & $0.000^{* * *}$ \\
Straightness & 0.61 & 0.64 & -3.872 & $0.000^{* * *}$ \\
Slope & 1.35 & 2.33 & -5.872 & $0.000^{* * *}$ \\
\hline & ${ }^{* * *}: p<0.001$. & &
\end{tabular}

The Mann-Whitney $U$ test shows that there are striking differences between socioeconomic groups and NRS access. First, the result related to socioeconomic characteristics is as follows. Areas with high access to the NRS show that the proportion of older people aged 65 and older tends to be greater. Meanwhile, areas with high accessibility to the NRS tend to have a high proportion of children under the age of 15. In addition, the proportion of single-person households is relatively high in neighborhoods with high accessibility. However, population density was not related to NRS access. Second, the differences according to the built environment are as follows: There were differences in housing types between accessible and low-access neighborhoods. Areas with high accessibility were a mixture of detached dwellings, apartments, and multi-family dwellings, and areas with low accessibility showed a high percentage of apartments. Moreover, the rate of dilapidated dwellings was higher in places with high accessibility. From the perspective of the road network, the straightness value was higher in areas with low accessibility. The slope was gentler in areas with high accessibility.

\section{Discussion}

The retail environment in the neighborhood needs to ensure equitable access in that it provides community places that provide daily necessities and services necessary for residents' daily life. Because of the characteristics of the NRSs, they may be sensitive to small changes in accessibility because it is mainly visited by walking. In particular, the elderly and low-income families are inevitably more sensitive because there are restrictions on transportation and housing options. Therefore, the main aim of this study is to investigate the accessibility of NRSs within walking distances by neighborhood and to explore whether inequality exists according to the socioeconomic or the built environment.

Through our analysis, we found that access to NRSs is equitable in terms of demographic and socioeconomic characteristics. NRS accessibility was higher in areas with less wealth, older people, and smaller family sizes. Considering the change in the retail environment in Seoul, which is currently reorganized mainly for large stores and online stores, social groups that are still in demand for offline stores and NRSs that supply goods and services to them are spatially close. The elderly are having difficulty adjusting to online shopping, and the low-income class has difficulty using a large mart located in a car-centered location. Single-person households tend to purchase various goods on a small scale and are more likely to use services rather than directly purchasing them. Studies targeting other 
cities have suggested reasons why the access of vulnerable groups is worse [26-28]. However, as the result of an equitable distribution of accessibility in terms of socioeconomic characteristics, studies of various cities are still necessary.

There were many differences in the architectural environment for accessibility. With the high density of housing in Korea, many apartment types have been deployed to solve this problem. In addition, old neighborhoods are being redeveloped into apartment complexes. Because of their high desirability, apartments are more expensive than low-rise housing, and relatively high-income people live in them. For apartments that form large blocks in Korea, NRSs are concentrated in the shopping mall building at the entrance. Apartment residents can easily access NRSs on foot, but the space in commercial buildings is limited, so the number of NRSs by type is relatively small. Moreover, because walls mainly surround the apartment complex, it is difficult for residents far from the apartment entrance to use the NRSs (Figure 4a).

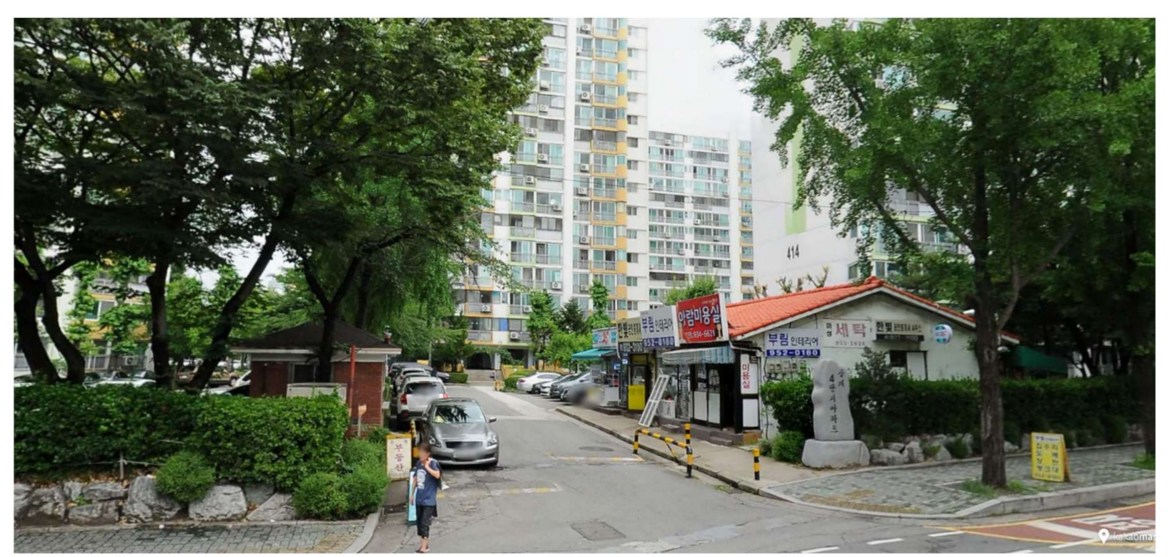

(a)

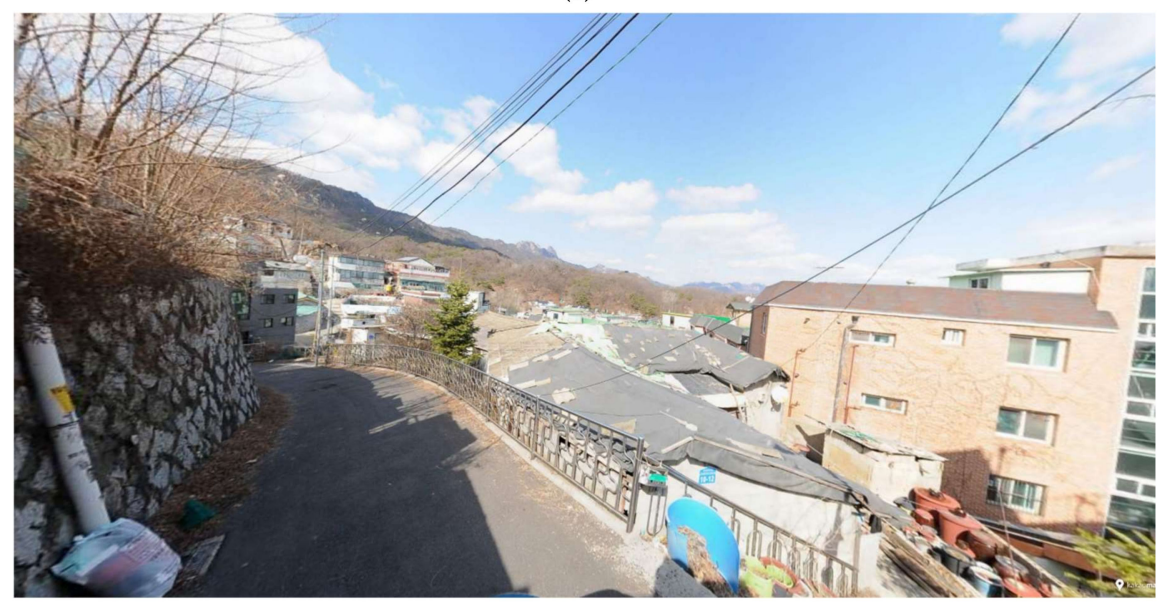

(b)

Figure 4. Built environment of inaccessible area: (a) apartment complex; (b) old hilly outskirts.

Another inaccessible area is the residential area located at the border of the city. These were mainly formed naturally rather than by urban planning. Therefore, the shape of the road network is irregular, and the parcels and blocks are small. In addition, most are in hilly areas with high slopes and stairs and many dead ends. When looking at the high straightness value, it may be possible to move with a shortcut, but the walking speed is bound to decrease with the slope. Among these, a place with development conditions has been newly developed, but the housing site with poor access conditions is aging and neglect (Figure $4 b$ ).

From the results of this study, urban planners can suggest the following implications for the private sector's NRSs when creating sustainable neighborhoods and inclusive cities. First, it is necessary to find 
a way to improve accessibility in areas with relatively little access such as large apartment complexes in Seoul. In addition, large apartment complexes affect the accessibility of the surrounding area, so detailed plans to interact with the surrounding area must be developed. For example, rather than building a mall at the entrance, one could improve the use of facilities inside and outside the complex by constructing a year-type mall at the border. In addition, it may be advantageous to increase pedestrian accessibility in the surrounding area by creating a public pedestrian passage in a closed apartment complex. Second, both relative and absolute accessibility to hilly areas was low. It is difficult for the underprivileged to choose housing when the housing environment deteriorates. Furthermore, low-income and the elderly are bound to rely on walking. If stores disappear within walking distance, the vulnerable can become more vulnerable to change. Therefore, a policy package is needed to maintain a relatively high level of accessibility to the NRS of the socially vulnerable. Third, it is necessary to measure changes in accessibility continuously. The commercial environment in Korea and Seoul is steadily changing. As regions with relatively good development conditions are replaced by commercial gentrification or convenient online shopping and service platforms, traditional retail and services such as grocery stores, hardware stores, barbershops, and laundries are gradually decreasing. Although vulnerable groups are currently relatively accessible, sustainability and regional inclusion must be ensured in view of the low online accessibility of socially vulnerable groups. Because the NRSs have economic and social functions within their neighborhoods, they should be preserved in areas with high accessibility. Therefore, future research should explore approaches to maintaining the positive elements of the NRSs while the commercial environment changes.

There is a limitation in that this study failed to consider various variables according to pedestrians and walking environments. To analyze the equity of accessibility, $10 \mathrm{~min}$, which is the universal walking time, was used as the critical distance. At this time, the walking speed was calculated to be about $3.6 \mathrm{~km} / \mathrm{h}$. However, it may vary depending on the actual pedestrian and walking environment. For example, older people may walk slower than this, and if the time to walk in hilly areas or wait for a crosswalk is added, the walking time may be longer. Therefore, it is necessary to analyze the accessibility more accurately in consideration of the environment's walkability and the vulnerable population.

\section{Conclusions}

This study focused on the differences and the equity of NRS pedestrian access according to socioeconomic status. The study of how accessibility and equity can be influenced by urban planning and urban form is an important issue in creating a more livable and sustainable urban environment. Many urban citizens value being able to access NRSs, select items, and use services within walking distance. Many studies since Jane Jacobs have emphasized the value of neighborhood commerce in the development of neighborhoods, but there is still a lack of empirical evidence and systematic knowledge of factors that influence neighborhoods' daily access to commercial use. NRS accessibility is determined by the built environment, which is not solely determined by land use. NRS should be located within walking distance of the inhabitants, and should be calculated from the actual pedestrian path, not from the Euclidean distance. There are many crowded shops on the street. The residential area is accessible because it can quickly meet the needs of the goods and services of the residents. To address this concern, we explored whether the NRS access was equal in all social groups through the case in Seoul. In general, there is a lot of literature that explores how the underprivileged population is located unfavorably, but the results of the Mann-Whitney $U$ test in this study appear to be favorable to the population group where the distribution of NRSs in Seoul is unfavorable. Because marginalized groups such as single-person households and the elderly are more likely to live in areas with better NRS access than other groups, the analysis results of the Mann-Whitney U test provide positive results in terms of social equity and accessibility to NRSs. However, marginalized populations live in aging residential areas where prices are low, and some of them have relatively poor access to NRSs. In particular, aging residential areas centered on hilly areas are left underdeveloped due to poor 
development conditions, and the accessibility of the NRSs, as well as the residential environment, may continue to deteriorate.

Author Contributions: Conceptualization, D.K. and J.P.; methodology, D.K.; software, D.K.; validation, J.P.; formal analysis, D.K. and J.P.; investigation, D.K. and J.P.; resources, D.K. and J.P.; data curation, D.K.; writing—original draft preparation, D.K.; writing—review and editing, J.P.; visualization, D.K.; supervision, J.P.; project administration, J.P.; funding acquisition, J.P. All authors have read and agreed to the published version of the manuscript.

Funding: This research was supported by the research fund of Hanyang University (HY-2018).

Conflicts of Interest: The authors declare no conflict of interest.

\section{Appendix A}

Table A1. The 36 businesses and selection criteria.

\begin{tabular}{|c|c|c|c|}
\hline KSIC Code & Category & Necessity & Frequency \\
\hline 5611 & Korean Food Restaurants & $X$ & $\mathrm{O}$ \\
\hline 56121 & Chinese Food Restaurants & $x$ & $\mathrm{O}$ \\
\hline 56122 & Japanese Food Restaurants & $X$ & $\mathrm{O}$ \\
\hline 56194 & Light Food Restaurants & $x$ & $\mathrm{O}$ \\
\hline 56123 & Western Food Restaurants & $x$ & $\mathrm{O}$ \\
\hline 56191 & Bakeries & $X$ & $\mathrm{O}$ \\
\hline 56192 & Fast Food Restaurants & $x$ & $\mathrm{O}$ \\
\hline 56193 & Chicken Restaurants & $x$ & $\mathrm{O}$ \\
\hline 5621 & Drinking Places & $x$ & $\mathrm{O}$ \\
\hline 5622 & Coffee Shops & $X$ & $\mathrm{O}$ \\
\hline 56129 & Other Foreign Food Restaurants & $x$ & $\mathrm{O}$ \\
\hline 42412 & $\begin{array}{c}\text { Building Completion and } \\
\text { Finishing }\end{array}$ & $\mathrm{O}$ & $x$ \\
\hline 96121 & Other Personal Care Services & $x$ & $\mathrm{O}$ \\
\hline 855 & Educational Institutes & $x$ & $\mathrm{O}$ \\
\hline 85631 & Foreign Language Institutes & $x$ & $\mathrm{O}$ \\
\hline 856 & Cultural and Sports Institutes & $x$ & $\mathrm{O}$ \\
\hline 68221 & Real Estate Brokerage & $\mathrm{O}$ & $x$ \\
\hline 96111 & Barber Shops & $\mathrm{O}$ & $\mathrm{O}$ \\
\hline 96112 & Beauty Salons & $\mathrm{O}$ & $\mathrm{O}$ \\
\hline 96912 & Laundry Services & $\mathrm{O}$ & $\mathrm{O}$ \\
\hline 91222 & Computer Game Room & $x$ & $\mathrm{O}$ \\
\hline 91223 & Singing Room & $X$ & $\mathrm{O}$ \\
\hline 47612 & Stationery Stores & $X$ & $\mathrm{O}$ \\
\hline 47611 & Book Stores & $X$ & $\mathrm{O}$ \\
\hline 47122 & Convenience Stores & $\mathrm{O}$ & $\mathrm{O}$ \\
\hline 472 & Grocery Stores & $\mathrm{O}$ & $\mathrm{O}$ \\
\hline 47312 & Communication Equipment Store & $\mathrm{O}$ & $x$ \\
\hline 474 & Clothing Stores & $\mathrm{O}$ & $X$ \\
\hline 47813 & Cosmetics Perfume Stores & $x$ & $\mathrm{O}$ \\
\hline 47511 & Hardware Stores & $\mathrm{O}$ & $\mathrm{O}$ \\
\hline 4771 & Gas Stations & $x$ & $\mathrm{O}$ \\
\hline 47851 & Florists & $x$ & $\mathrm{O}$ \\
\hline 47121 & Supermarkets & $\mathrm{O}$ & $\mathrm{O}$ \\
\hline 55101 & Hotels & $x$ & $x$ \\
\hline 55102 & Inns & $X$ & $x$ \\
\hline 55104 & Other General Accommodations & $X$ & $X$ \\
\hline
\end{tabular}




\section{References}

1. Gilart-Iglesias, V.; Mora, H.; Pérez-delHoyo, R.; García-Mayor, C. A Computational Method based on Radio Frequency Technologies for the Analysis of Accessibility of Disabled People in Sustainable Cities. Sustainability 2015, 7, 14935-14963. [CrossRef]

2. Shamsuddin, S.; Hassan, N.R.A.; Bilyamin, S.F.I. Walkable Environment in Increasing the Liveability of a City. Procedia Soc. Behav. Sci. 2012, 50, 167-178. [CrossRef]

3. Gilderbloom, J.I.; Riggs, W.W.; Meares, W.L. Does walkability matter? An examination of walkability's impact on housing values, foreclosures and crime. Cities 2015, 42, 13-24. [CrossRef]

4. Rao, F.; Summers, R.J. Planning for retail resilience: Comparing Edmonton and Portland. Cities 2016, 58, 97-106. [CrossRef]

5. Hong, Y.W.; Kim, J. Study on Store Visit Patterns and Territorial Consciousness in a Single-Family Residential Neighborhood in the Gangnam Region of Seoul TT-Study on Store Visit Patterns and Territorial Consciousness in a Single-Family Residential Neighborhood in the Gan. J. Korea Plan. Assoc. 2014, 49, 67-80. [CrossRef]

6. Bae, S.-H.; Park, S.-H. Changes of Social Functions and Roles of Neighborhood Small Shops-A Case Study of Hae-bang-chon in SeoulTT-Changes of Social Functions and Roles of Neighborhood Small Shops-A Case Study of Hae-bang-chon in Seoul. J. Urban Des. Inst. Korea Urban Des. 2015, 16, 21-36.

7. Fernandes, J.R.; Chamusca, P. Urban policies, planning and retail resilience. Cities 2014, 36, $170-177$. [CrossRef]

8. Soja, E.W. Seeking Spatial Justice; University of Minnesota Press: Minneapolis, MN, USA, 2013; Volume 16, ISBN 1452915288.

9. Yun, J.; Woo, M. Empirical Study on Spatial Justice through the Analysis of Transportation Accessibility of Seoul TT-Empirical Study on Spatial Justice through the Analysis of Transportation Accessibility of Seoul. J. Korea Plan. Assoc. 2015, 50, 69-85. [CrossRef]

10. Hegerty, S.W. Commercial bank locations and "banking deserts": A statistical analysis of Milwaukee and Buffalo. Ann. Reg. Sci. 2016, 56, 253-271. [CrossRef]

11. Walker, R.E.; Keane, C.R.; Burke, J.G. Disparities and access to healthy food in the United States: A review of food deserts literature. Health Place 2010, 16, 876-884. [CrossRef]

12. Neuman, S.B.; Moland, N. Book Deserts: The Consequences of Income Segregation on Children's Access to Print. Urban Educ. 2016, 54, 126-147. [CrossRef]

13. Camporeale, R.; Caggiani, L.; Fonzone, A.; Ottomanelli, M. Quantifying the impacts of horizontal and vertical equity in transit route planning. Transp. Plan. Technol. 2017, 40, 28-44. [CrossRef]

14. Jung, E.A.; Sung, H.G. Analysis of influencing relationship between transaction value of online shopping mall and sales by major retail store types. J. Korea Plan. Assoc. 2016, 51, 55-71. [CrossRef]

15. Yoon, Y.; Park, J. Stage Classification and Characteristics Analysis of Commercial Gentrification in Seoul. Sustainability 2018, 10, 2440. [CrossRef]

16. Ryu, H.-Y.; Park, J. A Study on the Variation Process of Commercial Gentrification Phase in Residential Area in Seoul-Focused on Business Type of Commercial Characteristics-TT_A Study on the Variation Process of Commercial Gentrification Phase in Residential Area in Se. J. Korea Plan. Assoc. 2019, 54, 40-51. [CrossRef]

17. Schuetz, J.; Kolko, J.; Meltzer, R. Are poor neighborhoods "retail deserts"? Reg. Sci. Urban Econ. 2012, 42, 269-285. [CrossRef]

18. Arranz-López, A.; Soria-Lara, J.A.; Pueyo-Campos, Á. Social and spatial equity effects of non-motorised accessibility to retail. Cities 2019, 86, 71-82. [CrossRef]

19. Garcia, X.; Garcia-Sierra, M.; Domene, E. Spatial inequality and its relationship with local food environments: The case of Barcelona. Appl. Geogr. 2020, 115, 102-140. [CrossRef]

20. Talen, E. The social equity of urban service distribution: An exploration of park access in pueblo, colorado, and macon, georgia. Urban Geogr. 1997, 18, 521-541. [CrossRef]

21. Meltzer, R.; Capperis, S. Neighbourhood differences in retail turnover: Evidence from New York City. Urban Stud. 2017, 54, 3022-3057. [CrossRef]

22. Park, S.; Choi, Y.; Seo, H.; Moudon, A.V.; Bae, C.-H.C.; Baek, S.-R. Physical activity and the built environment in residential neighborhoods of Seoul and Seattle: An empirical study based on housewives' GPS walking data and travel diaries. J. Asian Archit. Build. Eng. 2016, 15, 471-478. [CrossRef] 
23. Vragović, I.; Louis, E.; Díaz-Guilera, A. Efficiency of informational transfer in regular and complex networks. Phys. Rev. E 2005, 71, 36122. [CrossRef] [PubMed]

24. Anselin, L. Local Indicators of Spatial Association-LISA. Geogr. Anal. 1995, 27, 93-115. [CrossRef]

25. Anselin, L.; Syabri, I.; Kho, Y. GeoDa: An introduction to spatial data analysis. Geogr. Anal. 2006, 38, 5-22. [CrossRef]

26. Gordon, C.; Purciel-Hill, M.; Ghai, N.R.; Kaufman, L.; Graham, R.; Van Wye, G. Measuring food deserts in New York City's low-income neighborhoods. Health Place 2011, 17, 696-700. [CrossRef]

27. Laxy, M.; Malecki, K.C.; Givens, M.L.; Walsh, M.C.; Nieto, F.J. The association between neighborhood economic hardship, the retail food environment, fast food intake, and obesity: Findings from the Survey of the Health of Wisconsin Disease epidemiology_Chronic. BMC Public Health 2015, 15, 237. [CrossRef]

28. Bilal, U.; Jones-Smith, J.; Diez, J.; Lawrence, R.S.; Celentano, D.D.; Franco, M. Neighborhood social and economic change and retail food environment change in Madrid (Spain): The heart healthy hoods study. Health Place 2018, 51, 107-117. [CrossRef]

Publisher's Note: MDPI stays neutral with regard to jurisdictional claims in published maps and institutional affiliations.

(C) 2020 by the authors. Licensee MDPI, Basel, Switzerland. This article is an open access article distributed under the terms and conditions of the Creative Commons Attribution (CC BY) license (http://creativecommons.org/licenses/by/4.0/). 